\title{
PERIVASCULAR ADIPOSE TISSUE MODULATES VESSEL TONE IN HUMAN ARTERY
}

${ }^{1}$ Yu-Jing Gao Ph D, ${ }^{1}$ Zhao-Hua Zeng MD, ${ }^{2}$ Kevin Teoh MD, ${ }^{1}$ Robert MKW Lee PhD, ${ }^{2}$ Labib Abouzahr MD, ${ }^{2}$ Irene Cybulsky MD, ${ }^{2}$ Andre Lamy MD, ${ }^{2}$ Lloyd Semelhago MD

${ }^{1}$ Department of Anaesthesia, ${ }^{2}$ Cardiovascular Surgery, McMaster University, Hamilton, Ontario, L8N 3 Z5

\section{INTRODUCTION}

Recent studies have shown that adipose tissue is very active metabolically, and is producing a number of biologically active SUBSTANCES, ${ }^{1}$ IN addition to its role as a passicve storage for excess energy. IN the vascular system, virtually all the systemic blood vessels are surrounded by Perivascular adipose tissue (PVAT). Three studies have reported THAT PVAT from rat secretes a substance which can dilate the aorta ${ }^{2-3}$ and mesenteric artery. ${ }^{4}$ The purpose of the present study is to examine if this vasodilator is also present in the PVAT of human arteries.

\section{METHODS}

Remnants of human internal thoracic arteries, which are discarded during coronary artery bypass grafting, were used. Function of the artery was assessed with wire myography.

\section{RESULTS}

The presence of PVAT attenuated the contraction to phenylephrine and to $\mathrm{U} 46619$. To assess the direct effects of PVAT in inhibiting vasoconstriction, we did a bioassay experiment by transferring the bathing solution incubated with a PVAT-intact vessel (donor) to a vessel without PVAT (recipient) under the same precontracted condition. This transfer induced a significant relaxation in the recipient artery, while the same transfer procedure between PVAT-deprived arteries did not. Transfer of bathing solution with isolated PVAT induced a similar relaxation response as the bathing solution from PVAT-intact vessel. The relaxation was prevented by $\mathrm{KCl}$ $(60 \mathrm{mM})$. Calcium-dependent $\mathrm{K}^{+}$channel blocker, TEA $(1 \mathrm{mM})$ and iberiotoxin $\left(10^{-7} \mathrm{M}\right)$ completely blocked the relaxation, while voltage-dependent $\mathrm{K}^{+}$channel blocker 4-aminopyridine $(1 \mathrm{mM})$ and ATP-dependent $\mathrm{K}^{+}$channel blocker glibenclamide $(10 \mathrm{uM})$ did not.

\section{DISCUSSION}

The results suggest that in human internal thoracic arteries PVAT releases a transferable relaxing factor which acts through the activation of Kca channels. This may have clinical relevance because PVAT is removed by some surgeons during coronary artery bypass grafting, and preservation of PVAT may reduce spasm of the graft artery.

\section{REFERENCES:}

1. J Endocrinol Invest. 25:855-861.

2. FASEB J. 16:1057-1063.

3. Am J Physiol Heart Circ Physiol. 286:H1107-H1113.

4. Hypertension. 44:271-6. 